\title{
Porphyromonas gingivalis Differentially Modulates Apoptosome Apoptotic Peptidase Activating Factor 1 in Epithelial Cells and Fibroblasts

\author{
Isaac M. Bugueno, ${ }^{*}$ Fareeha Batool, * Linda Korah, ${ }^{*}$ Nadia Benkirane-Jessel, ${ }^{*}$ and Olivier Huck*
}

From INSERM 1260 Regenerative Nanomedicine, * Fédération de Médecine Translationnelle de Strasbourg (FMTS), Strasbourg; and the Faculty of Dental Surgery, Periodontology, ${ }^{\dagger}$ Université de Strasbourg, Strasbourg, France

Accepted for publication

October 3, 2017.

Address correspondence to Olivier Huck, D.D.S., Ph.D., Periodontology, Dental Faculty, 8 rue Sainte-Elisabeth, 67000 Strasbourg, France. E-mail: o. huck@unistra.fr.

\begin{abstract}
Porphyromonas gingivalis is able to invade and modulate host-immune response to promote its survival. This bacterium modulates the cell cycle and programed cell death, contributing to periodontal lesion worsening. Several molecular pathways have been identified as key triggers of apoptosis, including apoptosome apoptotic peptidase activating factor 1 (APAF-1). Apaf-1 and X-linked inhibitor of apoptosis protein (Xiap) mRNA were differentially expressed between gingival samples harvested from human healthy and chronic periodontitis tissues (Apaf-1, 19.2-fold; caspase-9, 14.5-fold; caspase3, 6.8-fold; Xiap: 2.5-fold in chronic periodontitis) $(P<0.05)$, highlighting their potential role in periodontitis. An increased proteic expression of APAF- 1 was also observed in a murine experimental periodontitis model induced by $P$. gingivalis-soaked ligatures. In vitro, it was observed that $P$. gingivalis targets APAF-1, XIAP, caspase-3, and caspase-9, to inhibit epithelial cell death at both mRNA and protein levels. Opposite effect was observed in fibroblasts in which $P$. gingivalis increased cell death and apoptosis. To assess if the observed effects were associated to APAF-1, epithelial cells and fibroblasts were transfected with siRNA targeting Apaf- 1 . Herein, we confirmed that APAF-1 is targeted by $P$. gingivalis in both cell types. This study identified APAF-1 apoptosome and XIAP as intracellular targets of $P$. gingivalis, contributing to the deterioration of periodontal lesion through an increased persistence of the bacteria within tissues and the subversion of host-immune response. (Am J Pathol 2018, 188: 404-416; https://doi.org/10.1016/j.ajpath.2017.10.014)
\end{abstract}

Periodontitis is a group of common chronic inflammatory diseases characterized by the destruction of tooth-supporting tissues and affecting $>30 \%$ to $50 \%$ of the adult population worldwide. ${ }^{1}$ The pathogenesis of periodontitis is related to the disruption of homeostasis between host-immune response and dysbiotic microbial flora at the lesion site. ${ }^{2}$ Periodontopathogenic bacteria, such as Porphyromonas gingivalis, Tannerella forsythia, and Treponema denticola interact with the host cells, including epithelial cells (ECs) and fibroblasts (FBs), aiming to colonize and bypass this barrier for invading the profound periodontal tissues. ${ }^{3} P$. gingivalis, a Gramnegative assacharolytic bacteria, is considered as one of the keystone pathogens involved in the transition from periodontal health to disease. ${ }^{4}$ This bacterium exhibits a wide array of virulence factors, including lipopolysaccharide ( $P g$-LPS), extracellular proteases, and several factors that contribute to its capability of cellular invasion such as fimbriae. ${ }^{5}$ Intracellular persistence is one strategy developed by the bacteria to escape the host-immune response, contributing to the pathologic process of periodontal diseases. ${ }^{6}$ This bacterium is also able to modulate cell cycle and programed cell death in an attempt to avoid the host-cell response and to promote its spread to distant sites. ${ }^{7,8}$ For instance, it has been observed that epithelial invasion by $P$. gingivalis subdues apoptosis and stimulates cell proliferation through modulation of several molecular triggers such as p53 and Janus kinase/Stat. ${ }^{9,10}$ However, the

Supported by INSERM and Faculté de Chirurgie Dentaire, Université de Strasbourg.

Disclosures: None declared. 
mechanisms involved remain under investigation, and several contradictory results have been observed about the influence of $P$. gingivalis on apoptosis and cell viability with some studies endorsing induction of apoptosis by infection. ${ }^{11,12}$ However, others have described its ability to inhibit such a process as a mechanism leading to induction of apoptosis. ${ }^{10,13}$

Apoptosis has been described as a potential mechanism involved in the extensive tissue destruction associated to infectious and inflammatory diseases such as gastric ulcer related to Helicobacter pylori, ${ }^{14}$ atherosclerosis, ${ }^{15}$ and chronic periodontitis (CP). ${ }^{12}$ Dysregulation of apoptosis-related genes, such as Bax, Bcl2, Nlrp3, or Smad2, has been observed in the gingival tissues of patients with periodontitis. ${ }^{16}$ Apoptosis is involved in homeostasis and is characterized by cellular morphologic changes, including cell shrinkage, DNA fragmentation, and engulfment by macrophages or neighboring cells. It is under the influence of regulators, including caspases that could be stated as key executioners of the cell death machinery. ${ }^{17}$ Apoptosis is induced by both extrinsic and intrinsic pathways. The intrinsic apoptosis pathway requires the release of proapoptotic factors from mitochondria, especially cytochrome $\mathrm{c}$ to the cytosol, which activates apoptosome-related components. ${ }^{18}$ The apoptosome complex is a cytosolic wheel-shaped signaling platform, constituted by the oligomerization of apoptotic peptidase activating factor 1 (APAF-1) ${ }^{19}$ induced by cytochrome $\mathrm{c}$ release that leads to the activation of several caspases, including caspase- 9 and -3 , and ultimately to apoptosis. ${ }^{20}$ APAF-1 apoptosome activity is controlled by several proteins such as X-linked inhibitor of apoptosis protein (XIAP) ${ }^{21}$ XIAP is a member of inhibitors of apoptosis proteins (IAPs) that is able to interact both directly with the activated caspases and under the control of activator of caspases such as second mitochondria-derived activator of caspase/direct inhibitor of apoptosis-binding protein with low pI. ${ }^{22}$ XIAP acts as a guard against accidental induction of the cell death program ${ }^{23}$ and may also be targeted by pathogens. ${ }^{24}$ Interestingly, it was already demonstrated that apoptosome expression is modulated by $P$. gingivalis in an endothelial cell model $^{25}$ with potential influence on atherosclerosis worsening. ${ }^{26}$ However, the effect of such infection at the periodontal level has not been investigated so far.

Therefore, the aim of this study was to evaluate the expression of APAF-1 in CP tissues in vivo. Simultaneously, the expression and enzymatic activities of key molecules related to apoptosome were examined in response to $P$. gingivalis infection in ECs and FBs in vitro, in an attempt to identify new molecular mechanisms associated to periodontitis onset.

\section{Materials and Methods}

\section{Ethics Statement}

A total of 20 patients accepted to participate in this study that received approval from the Ethic Committee (French Ministry of Research, Bioethic department authorization
DC-2014-2220). All patients gave written and informed consent before enrollment. Complete medical and dental histories were taken from all of the subjects.

\section{Study Population and Clinical Examination}

None of the patients had systemic diseases or cigarette smoking habit and had not taken any prior medications such as antibiotics in the past 3 months. Clinical periodontal examination included measurement of pocket probing depth and bleeding on probing at six sites around each tooth with a manual periodontal probe. The healthy group consisted of nine patients (five men and four women; mean age, $37.8 \pm 17.3$ years), and the $\mathrm{CP}$ group consisted of 11 patients (four men and seven women; mean age, $62.4 \pm 7.3$ years). Periodontal diagnosis of CP was based on the 1999 International World Workshop for a Classification of Periodontal Disease and Conditions. ${ }^{27}$

\section{Collection of Gingival Tissue Samples}

Gingival samples were obtained during periodontal surgeries (open access flap) or dental extractions. Samples were inserted immediately in a sterile tube and stored at $-80^{\circ} \mathrm{C}$ until RNA extraction.

\section{Bacterial Culture}

Porphyromonas gingivalis ATCC 33277 (ATCC, Manassas, VA) was cultured under strict anaerobic conditions at $37^{\circ} \mathrm{C}$ in brain-heart infusion medium (Sigma-Aldrich, St. Louis, MO), supplemented with $5 \mathrm{mg} / \mathrm{mL}$ hemin and $1 \mathrm{mg} / \mathrm{mL}$ menadione. On the day of infection, bacteria were collected and counted as previously described. ${ }^{25}$ To inactivate $P$. gingivalis (heat-killed $P$. gingivalis; $\mathrm{HPg}$ ), bacteria were heated at $85^{\circ} \mathrm{C}$ for 10 minutes before the beginning of the experiment. Commercial ultrapure $P g$-LPS was purchased from InvivoGen (San Diego, CA).

\section{Experimental Periodontitis}

After anesthesia, $P$. gingivalis-infected ligature was placed at the cervical palatal site of first and second maxillary molars of mice (C57/BL6; Charles River, Larbresle, France). Ligatures were replaced twice a week during 30 days as described previously. ${ }^{28}$ All procedures were approved by the local ethical committee and performed according to the regulations for animal experimentation. Mice were examined to evaluate pain and stress, and their weight was monitored daily.

\section{Immunohistochemistry}

Immunohistochemistry for APAF-1 has been performed on sections from $P$. gingivalis-infected mice and controls. Slides were treated as described in Saadi-Thiers et al. ${ }^{28}$ 
Briefly, after preliminary treatment, slides were incubated with primary antibody against APAF-1 (rabbit; PA5-19894; ThermoFischer, Illkirch, France) (dilution $1: 200$ ) at $4^{\circ} \mathrm{C}$ for 24 hours and then with peroxidase dog anti-rabbit $\operatorname{IgG}$ (dilution 1:200) for 30 minutes (ImmunoCruzTM rabbit ABC Staining System; Santa Cruz Biotechnology, Heidelberg, Germany). As a negative control, sections were treated with phosphate-buffered saline or with IgG as the primary antibody to rule out nonspecific binding. Finally, the sections were treated with diaminobenzadine as a substrate chromogen and counterstained with hematoxylin. The slides were then mounted and observed under a light microscope. ImageJ software version 1.5 (NIH, Bethesda, MD; http:// imagej.nih.gov/ij) was used to evaluate the relative protein expression of APAF-1 on both healthy and diseased tissues.

\section{Cell Culture}

Human oral ECs (GECs) used in this study derived from the TERT-2/OKF-6 cell line (BWH Cell Culture and Microscopy Core, Boston, MA). Cells were cultured at $37^{\circ} \mathrm{C}$ in a humidified atmosphere with $5 \% \mathrm{CO}_{2}$ in Defined Keratinocyte-serum-free basal medium supplemented with a cocktail of growth supplements (InvitroGen). Human oral FBs were isolated from gingival biopsy and cultivated in RPMI 1640 medium supplemented with 10\% fetal bovine serum (Life Technologies, Saint-Aubin, France), $2 \mathrm{mmol} / \mathrm{L}$ glutamine, $250 \mathrm{U} / \mathrm{mL}$ fungizone, and $10 \mathrm{U} / \mathrm{mL}$ antibiotics $(10 \mathrm{U} / \mathrm{mL}$ penicillin and $100 \mu \mathrm{g} / \mathrm{mL}$ streptomycin).

\section{Infection of GECs with $P$. gingivalis and Stimulation by} Its LPS

Twenty-four hours before the experiment, $2 \times 10^{5}$ cells were plated in each well of a 24-well plate. At the day of the experiment, cells were washed twice with phosphatebuffered saline and infected for 24 to 48 hours with $P$. gingivalis at a multiplicity of infection (MOI) of 100 and 10 bacteria/cell or stimulated by $1 \mu \mathrm{g} / \mathrm{mL} P g$-LPS and $1 \mu \mathrm{g} / \mathrm{mL}$ Escherichia coli-LPS for 24 to 48 hours.

\section{Metabolic Activity of Cells}

Metabolic activity/cell viability was measured with colorimetric AlamarBlue test (resazurin reduction test) ${ }^{29}$ (ThermoFischer). After 24 hours of infection, stimulation, or transfection, $300 \mu \mathrm{L}$ of incubation media was transferred to 96-well plates and measured at 570 and $600 \mathrm{~nm}$ to determine the percentage of AlamarBlue reduction.

\section{Flow Cytometric Analysis}

GECs and FBs were treated according to experimental design (infection, stimulation) as described. To measure apoptotic and necrotic cells, Annexin V-propidium iodide staining and flow cytometric analyses were performed. Briefly, after removal of the supernatant, cells were centrifuged and re-suspended. Cells were stained with AnnexinV-FLUOS Staining Kit (Roche Applied Science, Meylan, France) according to the manufacturer's instructions. For each condition, a total of 10,000 isolated cells were considered, using a wavelength of $488 \mathrm{~nm}$ for fluorescein and a wavelength of $617 \mathrm{~nm}$ for propidium iodide. BD LSR II was used for fluorimetric analysis. The percentage of Annexin V-positive cells was calculated from the quadrants (Qs) as follows: percentage of $\mathrm{Q} 1$ : positive cells for $\mathrm{IP}^{\mathrm{PE}}$ (necrosis), Q2: positive cells for Annexin $\mathrm{V}^{\mathrm{FITC}}$ and $\mathrm{IP}^{\mathrm{PE}}$ (late apoptosis), Q3: annexin-positive cells $\mathrm{V}^{\mathrm{FITC}}$ (apoptosis), Q4: unlabeled (viable cells).

\section{RNA Isolation and Reverse Transcription}

Total RNA from gingival samples and cells was extracted using Tri reagent (Sigma-Aldrich) according to the manufacturer's instructions. The total RNA concentration was quantified with NanoDrop 1000 (ThermoFischer). Reverse transcription was performed with the iScript Reverse Transcription Supermix (Bio-Rad, Miltry-Mory, France) according to the manufacturer's instructions.

\section{Real-Time Quantitative PCR Analysis}

To quantify mRNA expression, real-time quantitative PCR was performed on the cDNA samples. PCR amplification and analysis were performed with CFX Connect Real-Time PCR Detection System (Bio-Rad). Amplification reactions have been performed using iTAq Universal SYBR Green Supermix (Bio-Rad). $\beta$-actin was used as endogenous RNA control (housekeeping gene) in all samples. Primer sequences related to Bcl2, Bax1, Caspase-3, Caspase-9 were purchased from Qiagen (Les Ulis, France) and sequence for Apafl (3'GTCTGCTGATGGTGCAAGGA-5'; 5'-GATGGCCCGTGTGGATTTC-3'), keratin-10 (3'-CATGAGTGTCCCCCGGTATC$5^{\prime} ; 5^{\prime}$-CAGTATCAGCCGCTTTCAGA-3'), and Xiap (3'-TGGGACATGGATATACTCAGTTAACAA-5' $5^{\prime}$-GTTAGCCCTCCTCCACAGTGAA- $3^{\prime}$ ) were synthesized (ThermoFischer). The specificity of reaction was controlled with the melting curve analysis. The expression level was calculated after normalization to the housekeeping gene. All PCR assays were performed in triplicate, and results were represented by the mean values.

\section{Caspase Activity Fluorogenic Assays}

Caspase- 3 and -9 enzymatic activities were determined with specific fluorogenic enzymatic assays. Cells were sonicated, and lysates were incubated with $200 \mu \mathrm{L}$ of substrate solution (20 mmol/L HEPES, pH 7.4, 2 mmol/L EDTA, 0.1\% 3-[(3cholamidopropyl)dimethylammonio]-1-propanesulfonate, 5 $\mathrm{mmol} / \mathrm{L}$ dithiothreitol, and $0.75 \mu \mathrm{m}$ of caspase substrate) for 1 hour at $37^{\circ} \mathrm{C}$ as previously described..$^{30,31}$ The activity of 
each caspase was calculated from the cleavage of the respective specific fluorigenic substrate (AC-DEVD-AMC for caspase-3 and AC-LEHD-AMC for caspase-9) (Bachem, Bobendorf, Switzerland). Substrate cleavage was measured with a fluorescence spectrophotometer with excitation wavelength of $360 \mathrm{~nm}$ and emission at $460 \mathrm{~nm}$. Results were expressed as fluorescence units per milligram of total protein.

\section{Western Blot Analysis}

Proteins were separated by SDS/PAGE and transferred to a nitrocellulose membrane (Hybond ECL; Fischer Scientific, Illkirch, France). Primary antibodies were directed against APAF-1 (PA5-19894; ThermoFischer), XIAP (SC-11426; Santa Cruz Biotechnology), and $\beta$-actin (SC-130301; Santa Cruz Biotechnology). Proteins were visualized with secondary antibody conjugated to alkaline phosphatase (anti-mouse REF: A120-101AP; anti-rabbit REF: A90- 116AP; Bethyl Laboratories, Montgomery, TX). All antibodies were used at the dilutions recommended by the manufacturer.

\section{Terminal Deoxynucleotidyl Transferase Fluorescein-} dUTP Nick End Labeling

Direct terminal deoxynucleotidyl transferase fluoresceindUTP nick end labeling assay was performed using a commercially available kit (TACS 2 TdTDAB in situ apoptosis detection kit; Trevigen Inc., Gaithersburg, MD), according to the manufacturer's instructions.

\section{siRNA Transfection and XIAP Inhibition}

One day before the transfection, $5 \times 10^{6}$ cells were seeded in a 6-well plate. Transfection with $5 \mathrm{nmol} / \mathrm{L}$ of siRNA targeted against APAF-1 (SI00022792) or with negative control (Qiagen) was performed with a HiPerfect Transfection reagent, according to the manufacturer's protocol.

To inhibit XIAP, cells were pretreated with $50 \mathrm{mmol} / \mathrm{L}$ of Embelin (S7025; Selleckchem, Munich, Germany) diluted in $0.3 \%$ dimethyl sulfoxide 48 hours before infection. Cells were then infected according to the experimental design.

\section{Statistical Analysis}

Statistical analysis was performed with pairwise analysis of variance test and post hoc Tukey test. Statistical significance level was considered as $P<0.05$. Data were analyzed with Prism 6.0 (GraphPad Software, La Jolla, CA). All experiments have been performed in triplicate and in at least three sets of experiments.

\section{Results}

Expression Levels of Apoptosome-Related Components Are Modulated in Chronic Periodontitis

The expression of mRNAs related to Apaf-1, Xiap, caspase3 , and -9 was evaluated in gingival biopsies from healthy and CP patients to assess their potential relationship with periodontal lesion. Analysis showed that the expression of Apaf-1, caspase-3, and -9 mRNAs was significantly increased in the CP group (Apaf-1, 19.2-fold; caspase-9, 14.4-fold; caspase-3, 6.8-fold) $(P<0.05)$ (Figure 1, A, C, and D). However, the expression of the apoptosome inhibitor Xiap was decreased in the $\mathrm{CP}$ group (2.5-fold) (Figure 1B). The decrease of Xiap expression correlated with the increased expression of Apaf-1 as estimated with Spearman correlation test $(R=-0.5 ; P<0.05)$.

These results were also observed in vivo, in a murine model of experimental periodontitis associated to $P$. gingivalis infection (Figure 1, E-L). In the control group, Apaf-1 was detected mainly in soft tissues, especially within the epithelium (Figure 1, E-H). At the diseased site, Apaf-1 was still observed within the sulcular epithelium and also in the underlying connective tissue (Figure 1, I-L). No significant staining was observed in alveolar bone, suggesting a role for apoptosome mainly in the soft tissue compartment during $\mathrm{CP}$ pathogenesis.

\section{Infection with $P$. gingivalis Modulates Metabolic Activity in a Dose- and Cell-Dependent Manner}

To evaluate the impact of $P$. gingivalis infection on gingival cells, assessment of the metabolic activity of cells was evaluated in GECs and FBs (Figure 2). A dose-related effect has been observed in GECs regarding the metabolic activity of cells. At a high MOI (100), P. gingivalis increased significantly the metabolic activity of the GECs, whereas such an effect could not be observed with a low MOI (10) and $\mathrm{HPg}$ after 24 and 48 hours (Figure 2A). A cell-specific response has been observed. In FBs, infection with $P$. gingivalis reduced significantly the metabolic activity for each tested MOI (Figure 2B). In both cell types, $P g$-LPS displayed toxic effects at 48 hours (Figure 2, A and B).

\section{Increased EC Viability Is Correlated with Decreased Apoptotic Rate}

To evaluate the qualitative impact of $P$. gingivalis infection on cell death, apoptotic or necrotic state of infected cells was evaluated by flow cytometry. After 24 hours of infection, at high MOI (100), the increase of metabolic activity induced by $P$. gingivalis infection was correlated with a decrease in the apoptotic rate in GECs. No differences were observed between infection at MOI of 10 and uninfected cells (Figure 2, C and E). A cell-specific response has been 

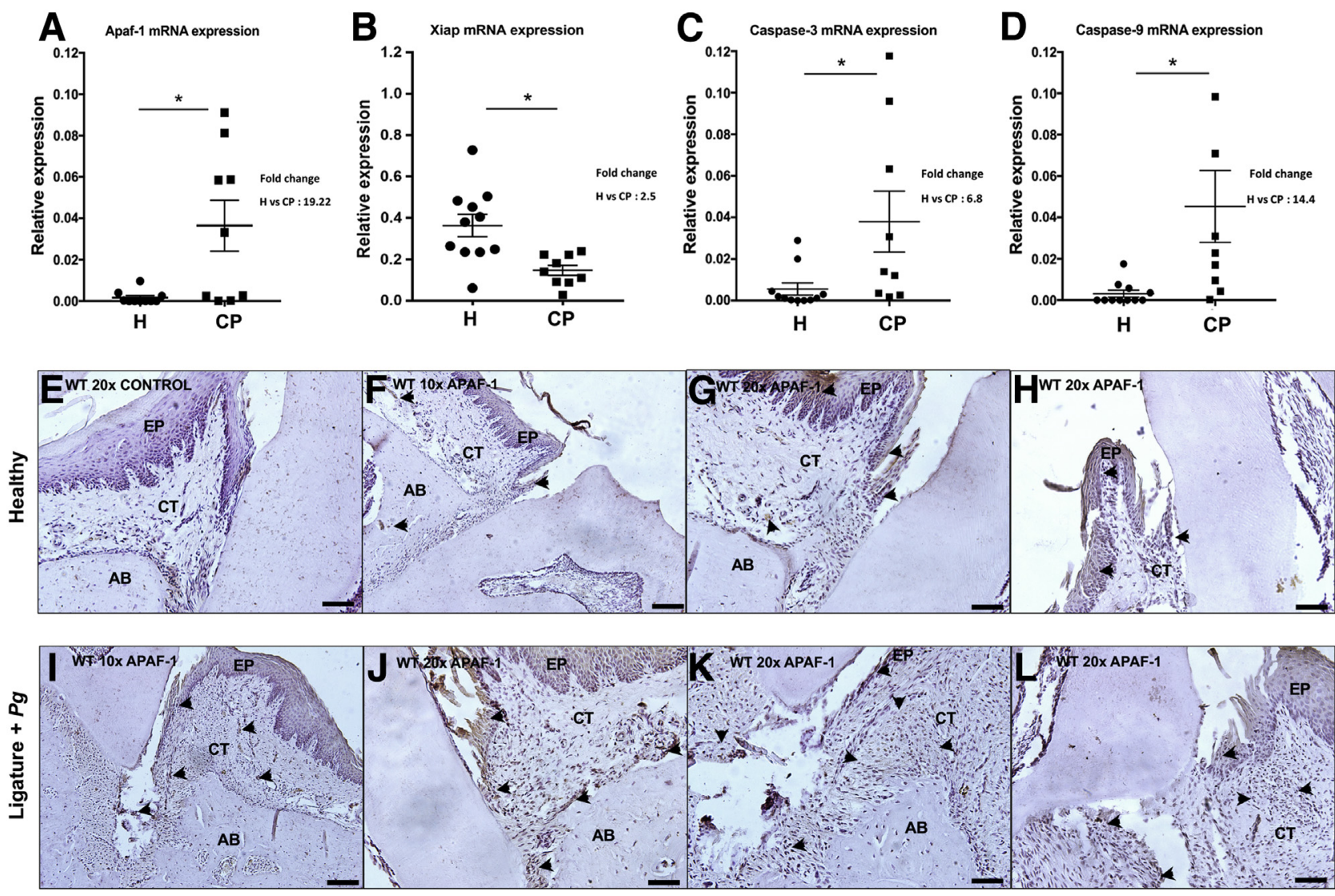

Figure 1 Apoptotic peptidase activating factor 1 (Apaf-1), caspase-3, caspase-9, and X-linked inhibitor of apoptosis protein (Xiap) mRNA expression in chronic periodontitis (CP). The mRNA expression levels were evaluated in the healthy $(\mathrm{H})$ and $\mathrm{CP}$ groups. mRNA expression was normalized against the expression level of $\beta$-actin. A-D: Relative expression of Apaf-1 (A), Xiap (B), caspase-3 (C), and caspase-9 (D). E-L: Apaf-1 expression in healthy periodontal tissue (left first molar) $(\mathbf{E}-\mathbf{H})$ and in experimental periodontitis induction (right first molar) $(\mathbf{I}-\mathbf{L})$, in wild-type mouse. Arrowheads indicate the zones of Apaf-1 expression. $n=10$ in the $\mathrm{H}$ group $(\mathbf{A}-\mathbf{D}) ; n=9$ in the CP group $(\mathbf{A}-\mathbf{D}) .{ }^{*} P<0.05$. Scale bars $=100 \mu \mathrm{m}$. AB, alveolar bone; CT, connective tissue; EP, epithelium; WT, wild-type.

observed, whereas, unlike GECs, the same conditions of infection and $P g$-LPS stimulation significantly increased apoptosis in FBs (Figure 2, D and F).

\section{Modulation of Apoptosome-Related mRNA Expression by $P$. gingivalis Infection}

To evaluate if intrinsic apoptosis-related pathways, especially associated to APAF-1 apoptosome, were modulated by $P$. gingivalis infection, mRNA expression was analyzed in infected GECs and FBs at 24 hours (Figure 3).

In GECs, $P$. gingivalis infection $(\mathrm{MOI}=100)$ decreased significantly Apaf-1 and caspase-3 mRNA expression $(P<0.05)$, and a descending trend was observed regarding caspase-9 mRNA expression as well (Figure 3, A and E). Of interest, the antiapoptotic B-cell lymphoma 2 (Bcl-2) and Xiap mRNAs were concomitantly increased and proapoptotic Bcl-2-associated $\mathrm{X}$ protein (Bax-1) was decreased (Figure 3A). An increase in keratin-10 expression has also been recorded, confirming the increased proliferation of GECs. When GECs were infected with a lower MOI (MOI $=10)$, opposite effects compared with those obtained with MOI of 100 have been observed, especially regarding Apaf-1 and caspase-3 expression (Figure 3, A and C). $P g$-LPS may be implicated in the observed effect because it induced a significant increase in the expression of Apaf-1 and caspase-3 mRNAs (Figure 3, C and E).

In FBs, $P$. gingivalis infection, at each tested MOI (10 and 100), increased significantly Apafl, caspase-3, and -9 gene expression (Figure 3, B-F). The same proapoptotic effects have been observed regarding Bcl-2/Bax-1 mRNA expression because infection leads to a decrease in Bcl-2 and an increase in Bax-1 mRNA expression. Interestingly, a toxic effect of $P g$-LPS has also been highlighted (Figure 3D).

Infection with $P$. gingivalis Modulates APAF-1 and XIAP Protein Levels and Enzymatic Activity of Caspases

To corroborate the results obtained at the gene level, protein concentrations of APAF-1, XIAP, and caspase-3 and -9 enzymatic activities have been measured. In GECs, 

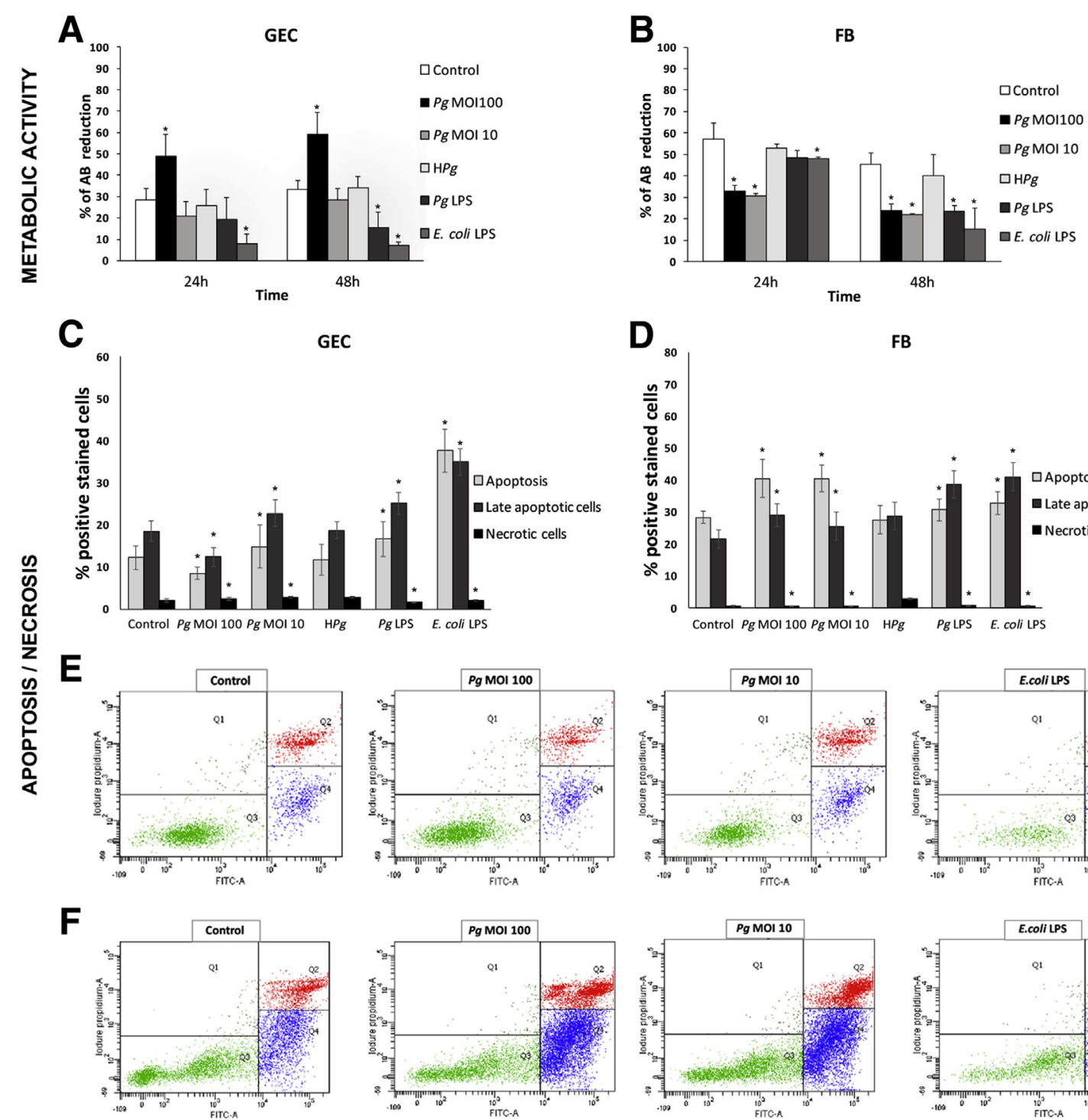

GEC

D
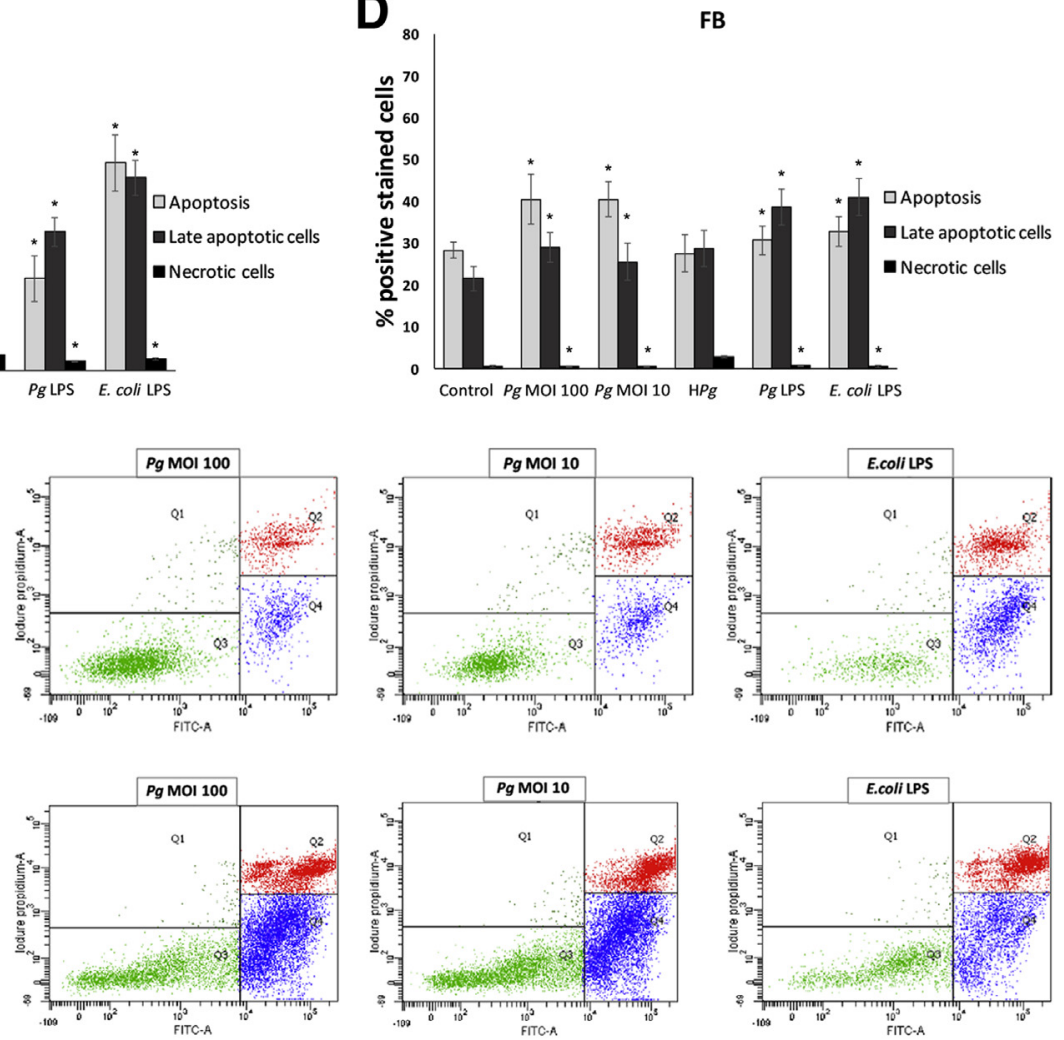

Figure 2 Effects of Porphyromonas gingivalis infection on cell metabolic activity and cell death. A: Metabolic activity of human oral epithelial cells (GECS) infected with $P$. gingivalis with multiplicity of infection (MOI) of 100 and MOI of 10, heat-killed $P$. gingivalis (HPg), and stimulated by $P g$-lipopolysaccharide (LPS) and Escherichia coli-LPS at 24 and 48 hours. B: Metabolic activity of fibroblasts (FBs) infected with $P$. gingivalis with MOI of 100 and MOI of 10, HPg, and stimulated by Pg-LPS and E. coli-LPS $(1 \mu \mathrm{g} / \mathrm{mL})$ at 24 and 48 hours. C: Analysis of cell death of GECs infected with $P$. gingivalis with MOI of 100 and MOI of 10, HPg, and stimulated by Pg-LPS and E. coli-LPS at 24 hours, by Annexin $\mathrm{V}^{\mathrm{FTTC}}$ and IP ${ }^{\mathrm{PE}}$ labeling measured by flow cytometry, showing apoptotic, late apoptotic, and necrotic cell populations. D: Analysis of cell death of FBs infected with $P$. gingivalis with MOI of 100 and M0I of 10 , $\mathrm{HPg}$, and stimulated by Pg-LPS and E. coli-LPS at 24 hours, by Annexin $\mathrm{V}^{\mathrm{FITC}}$ and IP $\mathrm{PE}^{\mathrm{PE}}$ labeling measured by flow cytometry, showing apoptotic, late apoptotic, and necrotic cell populations. E and F: Histogram of Annexin $\mathrm{V}^{\mathrm{FTTC}}$ and IP $\mathrm{P}^{\mathrm{PE}}$ labeling on GECS and FBs [quadrant (Q)1: IP $\mathrm{PE}^{\mathrm{PE}}$ positive cells; Q2:

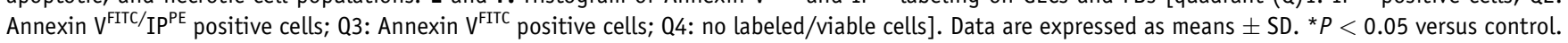
$A B$, alveolar bone; FITC, fluorescein isothiocyanate.

P. gingivalis $(\mathrm{MOI}=100)$ decreased significantly APAF-1 and increased XIAP concentrations, whereas $P$. gingivalis infection at MOI of 10 and $\mathrm{HPg}$ did not induce any modification (Figure 4, A, C and E). Similar to the trend observed for mRNA level, opposite results were obtained for APAF-1 in FBs because infection at both tested MOIs increased APAF-1 concentration (Figure 4, B, $\mathrm{D}$ and F). $P g$-LPS may be involved because XIAP concentration was decreased after $P g$-LPS stimulation in GECs.
Caspases are major components of apoptosome-related pathways because they are key activators of apoptosis. In our model, infection modulated caspase-9 and -3 enzymatic activities in a dose-dependent manner. In GECs, for MOI of 100, the enzymatic activity of both caspases was decreased, whereas at MOI of 10 , an increase was measured. Intriguingly, $P g$-LPS did not modify caspase-3 enzymatic activity; however, it seemed to be implicated in the activation of caspase-9. In FBs, $P$. gingivalis infection increased caspase-3 significantly. Of interest, an 

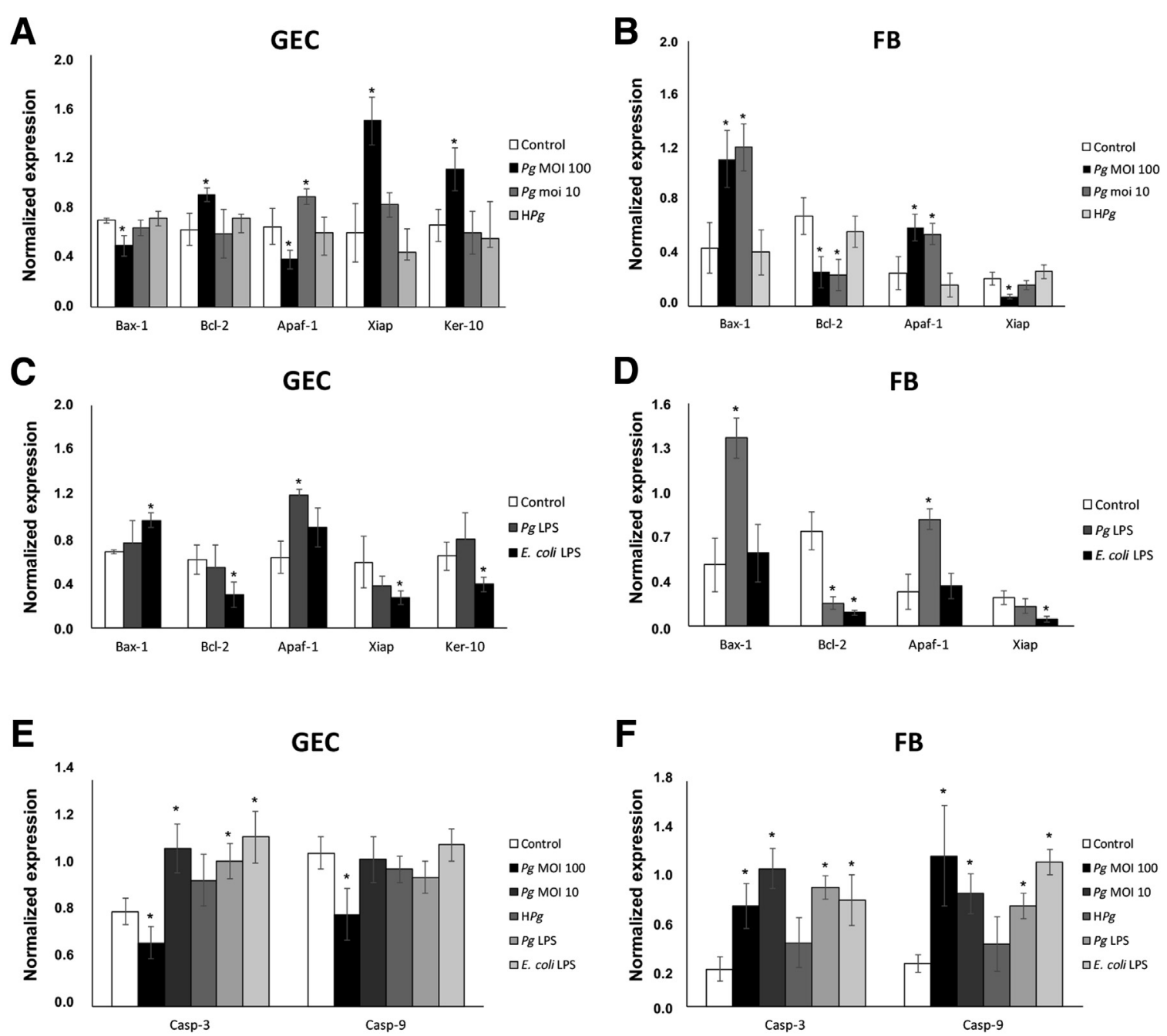

$\mathbf{F}$

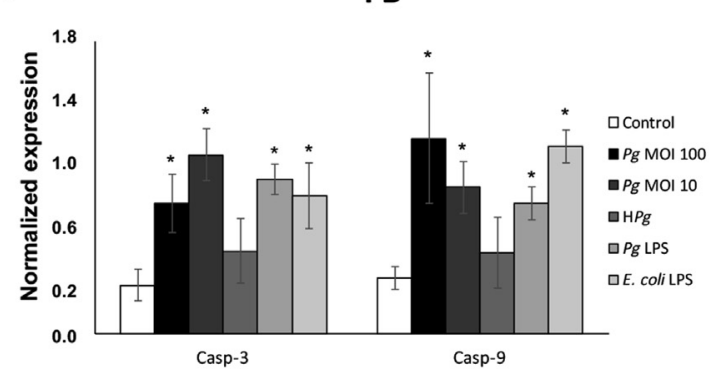

Figure 3 Porphyromonas gingivalis and its lipopolysaccharide (LPS) differentially modulates apoptosis-related gene expression in human oral epithelial cells (GECs) and human oral fibroblasts (FBs). A: Gene expression of Bax-1, Bcl-2, Apaf-1, Xiap, and Ker-10 in GECs infected with $P$. gingivalis with multiplicity of infection (MOI) of 100 and MOI of 10 and heat-killed $P$. gingivalis (HPg) at 24 hours. B: Gene expression of Bax-1, Bcl-2, APAF-1, and Xiap in FBs infected with P. gingivalis with MOI of 100 and MOI of 10 and HPg at 24 hours. C: Gene expression of Bax-1, Bcl-2, Apaf-1, Xiap, and Ker-10 in GECs stimulated by PgLPS and Escherichia coli-LPS $(1 \mu \mathrm{g} / \mathrm{mL})$ at 24 hours. D: Gene expression of Bax-1, Bcl-2, Apaf-1, and Xiap in FBs stimulated by Pg-LPS and E. coli-LPS (1 $\mu \mathrm{g} / \mathrm{mL})$ at 24 hours. E: Gene expression of caspase-1, -3 , and -9 in GECs infected with $P$. gingivalis with MOI of 100 and MOI of 10, HPg, and stimulated by Pg-LPS and E. coli-LPS $(1 \mu \mathrm{g} / \mathrm{mL})$ at 24 hours. F: Gene expression of caspase-1, -3 , and -9 in FBs infected with $P$. gingivalis with MOI of 100 and MOI of 10, HPg, and stimulated by $P g$-LPS and $E$. coli-LPS $(1 \mu \mathrm{g} / \mathrm{mL})$ at 24 hours. Data are expressed as means \pm SD. ${ }^{*} P<0.05$ versus control. Casp, caspase.

increase in caspase-9 activity was also observed after $P g$-LPS stimulation (Figure 5).

\section{P. gingivalis Modulates Cell Survival and Cell Death in Infected GECs and FBs through APAF-1 and XIAP Modulation}

To evaluate if APAF-1 was a key effector of cell death associated to $P$. gingivalis infection, RNA silencing was performed with siRNA targeting APAF-1 in GECs and FBs. Metabolic activity, ratio of apoptosis and necrosis, and enzymatic activity of caspases were measured after Apaf-1 RNA silencing in GECs and FBs.

In transfected GECs, infection at high MOI did not increase metabolic activity. Furthermore, the inhibition of APAF-1 was associated to an increase in the metabolic activity of cells at low MOI, highlighting the role of apoptosome in the response of cells to $P$. gingivalis (Figure 6A). In FBs, an opposite effect was observed, confirming the differential mechanisms involved in relation to cell type (Figure 6B). A qualitative change has also been observed regarding the type of cell death induced. When transfected cells were infected with $P$. gingivalis, an increase in apoptosis was observed in comparison with the negative control and $\mathrm{HPg}$ in GECs (Figure 6C). Of interest, such result was correlated with an increase in caspase-3 activity (Figure 6E). As observed for metabolic activity, contradictory effects were observed in FBs compared with that in GECs (Figure 6, $\mathrm{B}, \mathrm{D}$ and $\mathrm{F}$ ).

To determine the implication of XIAP, cells were treated with Embelin, an XIAP inhibitor, before infection. In 


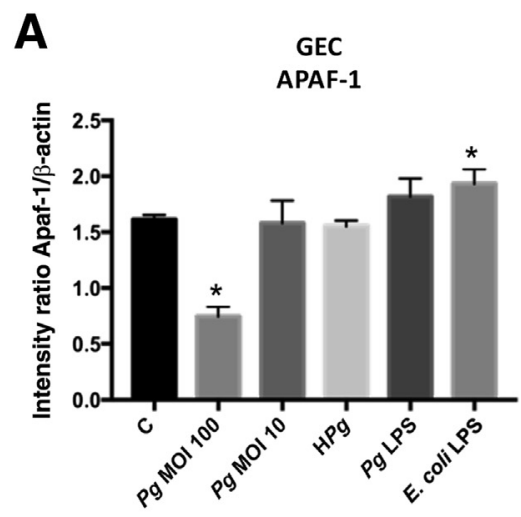

B

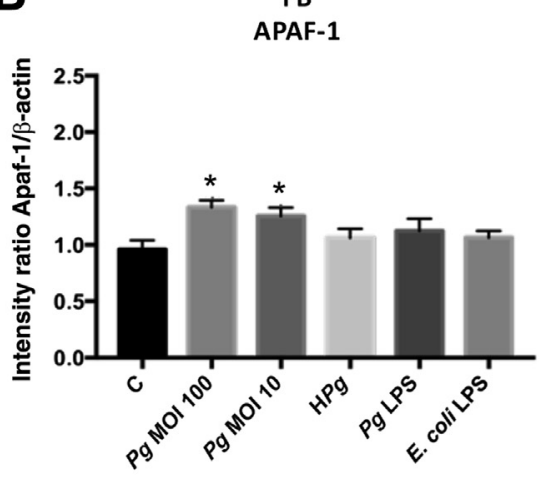

C

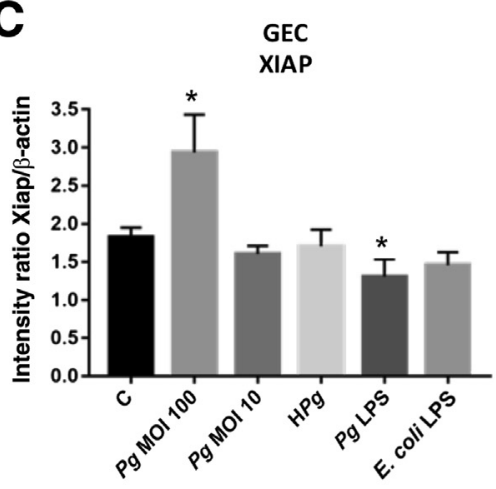

E

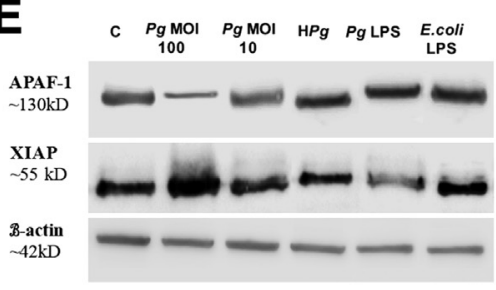

D

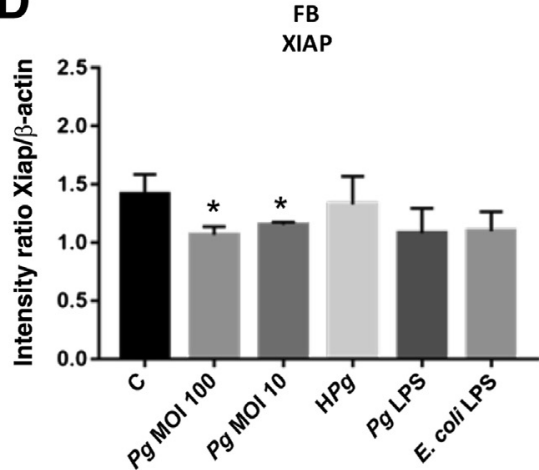

$\mathbf{F}$

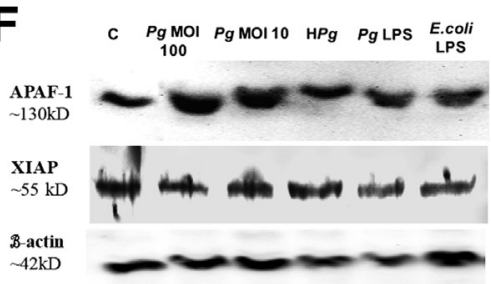

Figure 4 Porphyromonas gingivalis modulates apoptotic peptidase activating factor 1 (APAF-1) and X-linked inhibitor of apoptosis protein (XIAP) protein concentration in human oral epithelial cells (GECs) and human oral fibroblasts (FBS). A, C, and E: Western blot analysis for APAF-1 and XIAP in GECs infected with $P$. gingivalis with multiplicity of infection (MOI) of 100 and MOI of 10, heatkilled $P$. gingivalis $(\mathrm{HPg})$, and stimulated by $P g$ lipopolysaccharide (LPS) and Escherichia coli-LPS $(1 \mu \mathrm{g} / \mathrm{mL})$ at 24 hours. B, D, and F: Western blot analysis for APAF-1 and XIAP proteins in FBs infected with $P g$ with MOI of 100 and MOI of 10 , HPg, and stimulated by Pg-LPS and E. coli-LPS $(1 \mu \mathrm{g} / \mathrm{mL})$ at 24 hours. ${ }^{*} P<0.05$ versus control. C, control.
GECs, the increase of metabolic activity induced by $P$. gingivalis $(\mathrm{MOI}=100)$ infection was inhibited (Figure 7A) and was correlated with increased apoptosis and caspases activity (Figure 7, C and E). In FBs, pretreatment with Embelin did not modulate cellular metabolic activity (Figure 7B) in infected cells. However, a qualitative change related to the type of cell death induced was observed (Figure 7D).
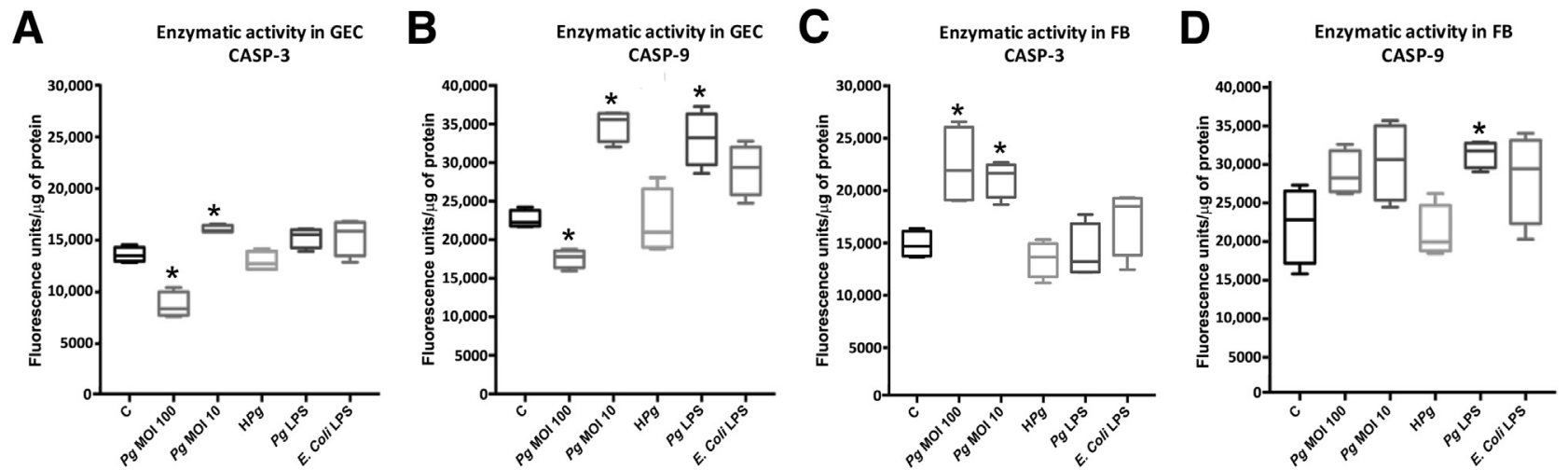

Figure 5 Porphyromonas gingivalis and its lipopolysaccharide (LPS) modulate enzymatic activity of caspases in a dose- and cell-dependent manner. Enzymatic activity of caspase-3 (A and $\mathbf{C}$ ) and caspase-9 (B and $\mathbf{D})$ in human oral epithelial cells (GECs) and human oral fibroblasts (FBs) infected with $P$. gingivalis with multiplicity of infection (MOI) of 100 and MOI of 10, heat-killed $P$. gingivalis (HPg), and stimulated by Pg-LPS and Escherichia coli-LPS (1 $\mu \mathrm{g} / \mathrm{mL})$ at 24 hours. Data are expressed as means \pm SD. ${ }^{*} P<0.05$ versus control. $C$, control; CASP, caspase. 

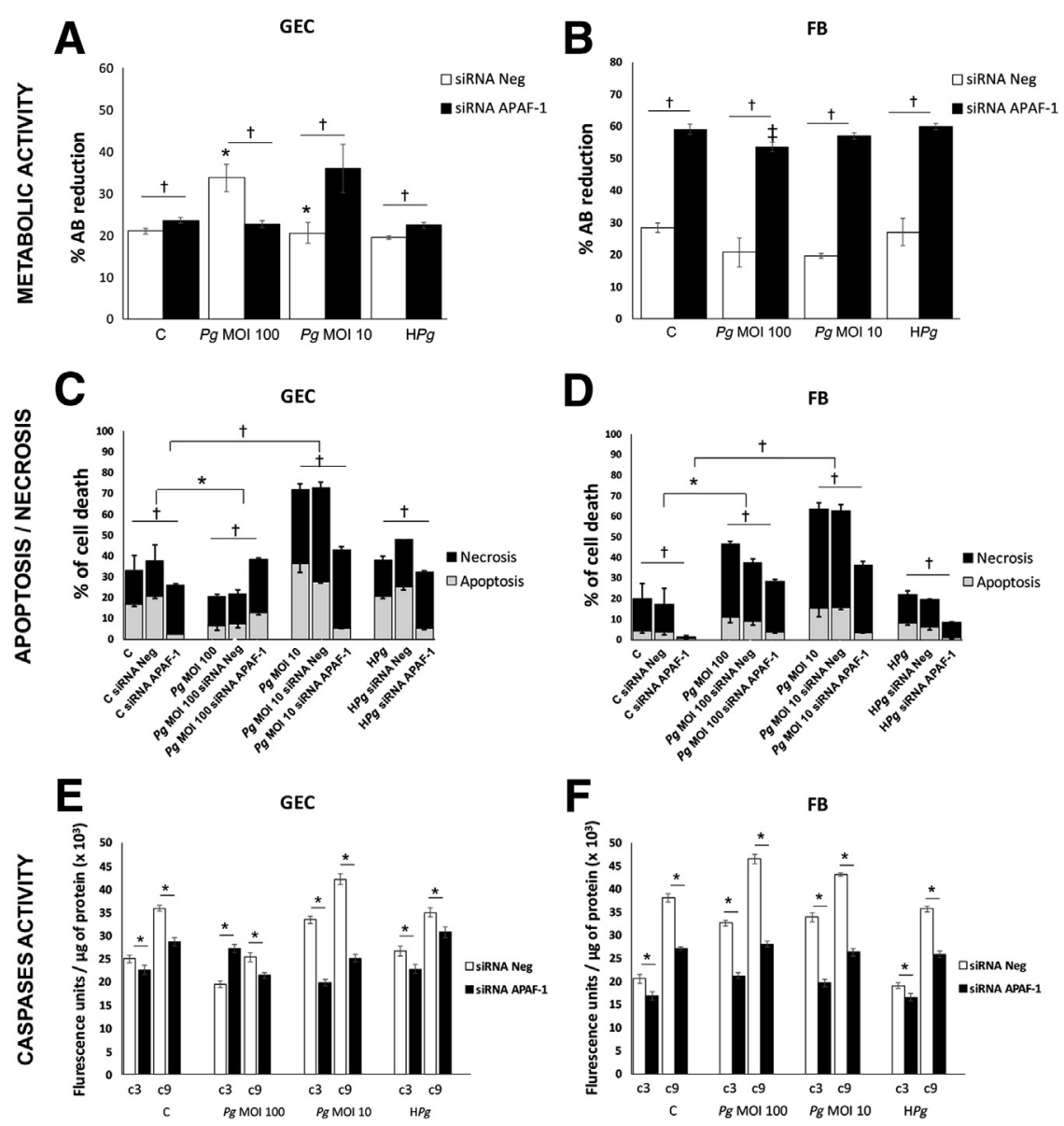

Figure 6 Porphyromonas gingivalis modulates cell survival and apoptosis rate in infected human oral epithelial cells (GECs) and human oral fibroblasts (FBs) through apoptosome-related proteins. A and B: Metabolic activity of GECs and FBs transfected with siRNA targeting apoptotic peptidase activating factor 1 (APAF-1) and infected with $P$. gingivalis with multiplicity of infection (MOI) of 100, MOI of 10, and heat-killed $P$. gingivalis $(\mathrm{HPg})$ at 24 hours. C and D: Apoptosis/necrosis ratio, in transfected GECs and FBs and infected with $P$. gingivalis with MOI of 100 , MOI of 10 , and $\mathrm{HPg}$ at 24 hours. $\mathbf{E}$ and $\mathbf{F}$ : Enzymatic activity of caspase-3 (c3) and caspase-9 (c9) in transfected GECs and FBs and infected with $P$. gingivalis with MOI of 100, MOI of 10 , and $\mathrm{HPg}$ at 24 hours. Data are expressed as means \pm SD. ${ }^{\star} P<0.05$ versus control; ${ }^{\dagger} P<0.05 ;{ }^{\ddagger} P<0.05$ versus transfected control. $A B$, alveolar bone; $C$, control.

\section{Discussion}

This study aimed at determining the ability of $P$. gingivalis to modulate APAF-1 apoptosome activity and programed cell death in the periodontal soft tissue cells. First, in gingival samples from periodontitis patients, an increase of Apaf- 1 expression and a decrease of its inhibitor, Xiap, was demonstrated, showing that APAF-1 apoptosome may be involved in the periodontal lesion. However, this difference in terms of gene expression may also be related to changes of the cellular composition of the analyzed samples with $\mathrm{CP}$ samples exhibiting more inflammatory cells than healthy ones. In an in vivo model of experimental periodontitis, an increased expression of APAF-1 was observed at the diseased site, especially at the connective tissue level, consolidating our hypothesis.

In vitro, $P$. gingivalis acted differentially on this specific pathway according to the MOI and cell type. Herein, we observed an augmentation in EC viability, correlated with a decrease in apoptosis triggers (APAF-1, caspases) and an increase of apoptosis inhibitors (XIAP), when cells were infected at a high MOI. In addition, when XIAP was inhibited, the increased proliferation of GECs was counteracted. Such effect was not observed in FBs.
Because of their specific location at the interface between subgingival biofilms and gingival sulcus, ECs constitute the first line of host defense. Integrity of the epithelial barrier is a key factor for periodontal health because ECs play a key role in the overall tissue homeostasis and initiation of innate immune response. ${ }^{5}$ Not only do these cells release soluble mediators such as cytokines ${ }^{32}$ that sustain the inflammatory process but also antimicrobial peptides such as $\beta$-defensins. ${ }^{33} P$. gingivalis is considered as one of the keystone pathogens and is able to modulate cell cycle and programed cell death to favor its survival. ${ }^{7,34}$ Cellular invasion by $P$. gingivalis is followed by intracellular persistence, bacterial multiplication, and leads to bacterial spread to adjacent tissues, including connective tissue and bone. ${ }^{35}$ Moreover, several studies showed that this bacterium uses a panel of strategies to hijack host mechanisms such as autophagy. ${ }^{36}$ In this study, it was confirmed that $P$. gingivalis infection inhibits apoptosis and increases the proliferation rate of ECs. This result is in accordance with the previous studies ${ }^{7,9,10,13}$ that implicated the dysregulation of cell cycle by bacteria during the pathogenic process. ${ }^{8,25}$ Recently, the importance of cell cycle in the invasion process of $P$. gingivalis has been demonstrated, because the bacteria preferentially target cells in the $\mathrm{S}$ phase. ${ }^{37}$ This 

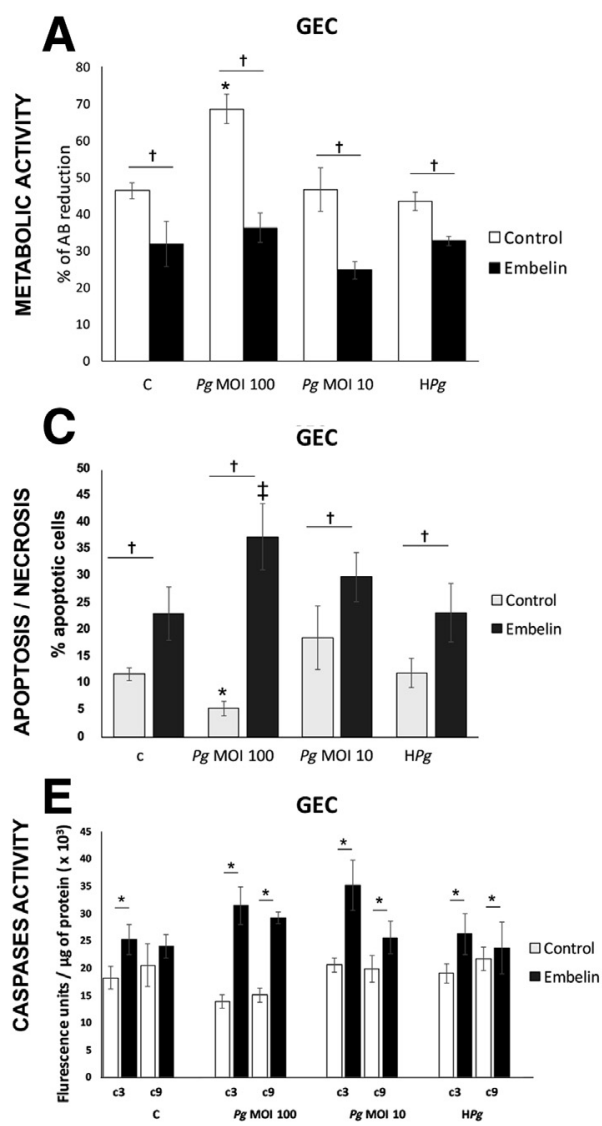

B

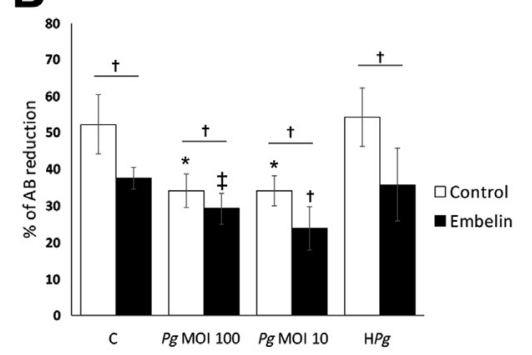

D

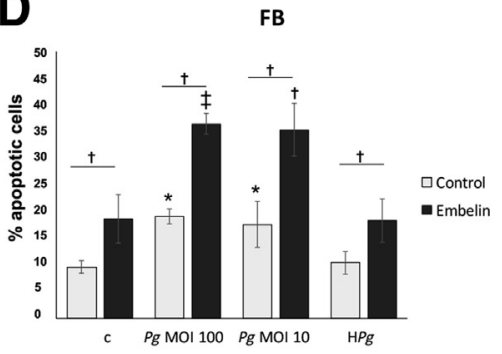

$\mathbf{F}$

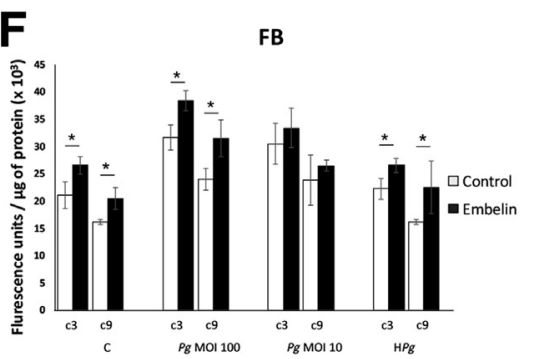

Figure 7 Porphyromonas gingivalis modulates cell survival and apoptotic rate in human oral epithelial cells (GECS) and human oral fibroblasts (FBs) through apoptosome-related proteins. A and B: Metabolic activity of GECs and FBs treated with Embelin during 48 hours and infected with $P$. gingivalis with multiplicity of infection (MOI) of 100 , MOI of 10, and heat-killed $P$. gingivalis (HPg) at 24 hours. C and D: Apoptosis evaluation by terminal deoxynucleotidyl transferase-mediated dUTP nick-end labeling assay in transfected GECs and $\mathrm{FBs}$ and infected with $P$. gingivalis with MOI of 100, MOI of 10, and HPg at 24. E and F: Enzymatic activity of caspase-3 (c3) and caspase-9 (c9) in transfected GECs and FBs and infected with $P$. gingivalis with MOI of $100, \mathrm{MOI}$ of 10 , and $\mathrm{HPg}$ at 24 hours. Data are expressed as means \pm SD. ${ }^{*} P<0.05$ versus control; ${ }^{\dagger} P<0.05$ for differences between pretreated and nontreated cells; ${ }^{\ddagger} P<0.05$ versus pretreated control. $\mathrm{AB}$, alveolar bone; $C$, control. increase, in terms of proliferation rate, has prominent clinical consequences because it was suggested that fast turnover of ECs may reduce immune response at the sulcular level. ${ }^{9}$ Moreover, this may also have influence on cellular senescence that has been associated to impaired innate immune response, increased oxidative stress and that reduce bacterial clearance. ${ }^{38-40}$ Contradictory results could also be found, and some studies described an increased EC death induced by $P$. gingivalis infection. Such discrepancies were already observed by Stathopoulou et $\mathrm{al}^{12}$ and might be explained by the different protocols used (MOI, bacterial strain, length of exposure, cell type). ${ }^{11}$

In FBs, the effects observed were similar to those in endothelial cells, ${ }^{25}$ whereas opposite outcomes in comparison with GECs were noticed, highlighting the differential effect of the infection according to cell type. This result is in accordance with previous studies that showed the cytotoxic effect of $P$. gingivalis on $\mathrm{FBs}^{41}$ but differs from those observed in periodontal ligament fibroblasts. ${ }^{42}$ This reduction of proliferation rate diminishes the capability of the host to regenerate or to repair the injured tissues and contributes to worsening of periodontal lesions. ${ }^{43}$

Apoptosis is a well-described cellular process and plays a key role in homeostasis, and its dysregulation has been associated to periodontitis. ${ }^{16}$ Modulation of apoptosis or programed cell death by periodontal pathogens is an important feature of the disease, especially at the epithelial level where antiapoptotic effects and therefore prosurvival cellular phenotype will be a key mechanism of bacterial colonization $^{10}$ and to sustained inflammation. For instance, reduced apoptosis within periodontal tissues correlates with chronic persistence of inflammatory cells. ${ }^{44}$ It has been described that $P$. gingivalis-induced effects on apoptosis regulation depend on cell type and associated with the modulation of several pathways such as phosphatidylinositol 3-kinase/Akt or Janus kinase/Stat pathways. ${ }^{10,34}$ In this study, we focused on the APAF-1-related pathway that has been described as an important component of the mitochondria-mediated intrinsic pathway. ${ }^{45}$ It was observed that $P$. gingivalis modulates significantly the expression of APAF-1 in a cell- and dose-dependent manner. In ECs, at high dose, $P$. gingivalis blocked cell death through a decrease in APAF-1 expression, reduction in the enzymatic activity of caspases, and an increase in XIAP expression. APAF-1 has already been described as a target of several pathogens, including bacteria such as Chlamydia pneumo$n_{i a e^{46}}$ or viruses such as Influenza A virus. ${ }^{47}$ The decrease of APAF-1, at both mRNA and protein levels, may explain the increased metabolic activity observed. Therefore, it can be hypothesized that such dysregulation may be a specific bacterial strategy to avoid clearance from the organism with potential consequences regarding induction of inflammatory 


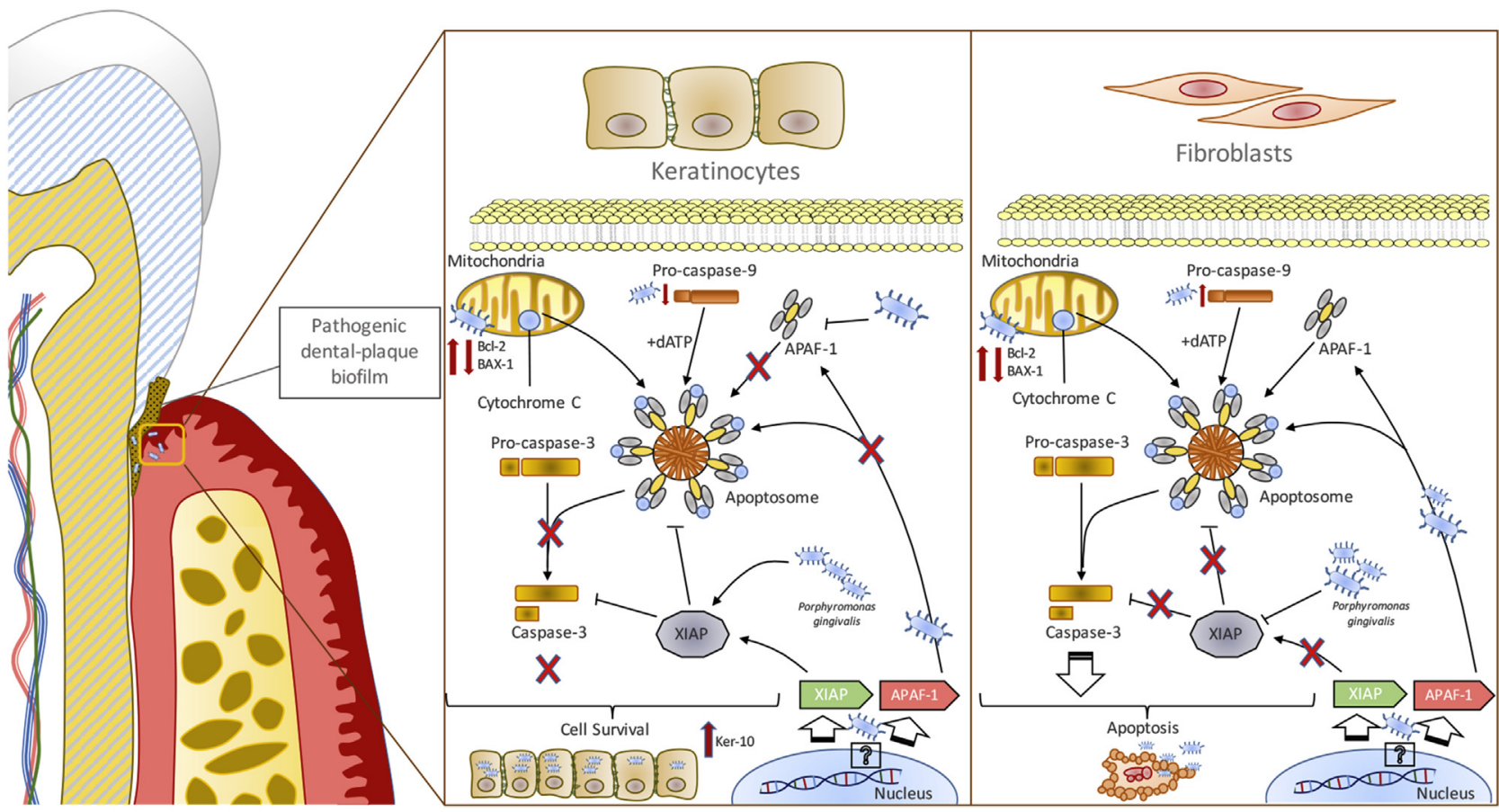

Figure 8 Cell death and activation of apoptotic peptidase activating factor 1 (APAF-1)-related pathway in response to Porphyromonas gingivalis infection in epithelial cells and fibroblasts. Cell-specific modulation of apoptosis by $P$. gingivalis in epithelial cells and fibroblasts. In epithelial cells, $P$. gingivalis decreases APAF-1 and increases X-linked inhibitor of apoptosis protein (XIAP) expression, leading to an augmented cell survival. However, in fibroblasts, bacteria stimulate APAF-1 pathway and reduce XIAP expression, inducing apoptosis. Bax-1, Bcl-2-associated X protein; Bcl-2, B-cell lymphoma 2.

cell death through necrosis or necroptosis as suggested in a mouse model. ${ }^{48}$ The regulatory role of XIAP has also been investigated by using an inhibitor. In our model of ECs, inhibition of XIAP inhibited the $P$. gingivalis-induced increase of cell viability. This effect was associated with an elevated caspase-3 and -9 enzymatic activity, as already demonstrated in other cellular models. ${ }^{22,49}$ IAPs, such as cIAP1, cIAP2, and XIAP, are key elements of homeostasis because their loss or inhibition sensitizes the cell to death associated to inducers such as tumor necrosis factor $(\mathrm{TNF}) .^{50} \mathrm{~A}$ better understanding of mechanisms involved between IAP and regulation of cell death will be instrumental in developing therapeutic strategies. In FBs, inhibition of XIAP did not affect $P$. gingivalis-associated cell death as hypothesized. However, it is important to consider the multitude of pathways that control apoptosis process and crosstalk between them especially in the context of $P$. gingivalis infection. For instance, $P$. gingivalis is able to modulate NLR family pyrin domain containing 3 (NLRP3) inflammasome expression. ${ }^{51,52}$ NLRP3 inflammasome is implicated in the release of mature IL-1 $\beta$ and IL-18 and to pyroptosis but also in the control of apoptosis as demonstrated in osteoblasts infected by Aggregatibacter actinomycetemcomitans. ${ }^{53}$ Interestingly, inflammasome and apoptosome are similar in their structure and are subject to crosstalk mediated by cytochrome c. ${ }^{54}$ Future studies need to focus on the effect induced by apoptosome modulation by $P$. gingivalis on inflammasome activity and especially on its impact on sustained periodontal inflammation.
A differential cellular effect was also observed between high and low doses of infection. To date no MOI has been regarded as the most relevant to the in vivo situation, even if MOI of 100 corresponds to the optimal dose for $P$. gingivalis invasion ${ }^{6}$; however, the use of a low and high MOI may give some data relevant to low-grade versus acute infection. We could hypothesize that in case of high bacterial load, as observed in deep pockets that occur during severe forms of periodontitis, host defense is submerged by the bacterial aggression, leading to an unregulated cellular proliferation. In case of low bacterial charge, host defense is able to control bacterial spreading and to eliminate infected cells more efficiently. Hence, it may be considered that apoptosome may be positive in the case of mild infection but detrimental in the case of severe infection. Such effect has already been observed with regard to another molecular platform, the inflammasome, ${ }^{55}$ in an infectious context. Here, we showed that APAF-1 was increased in periodontitis, based on clinical biopsies and ligature-induced experimental periodontitis analyses. However, even if we can suppose that high bacterial load was associated to the analyzed tissues, no bacterial sampling was available, restraining the possibility to directly assess the correlation between $P$. gingivalis presence and APAF-1 expression. Furthermore, even if relevant to study periodontal pathogenesis ${ }^{56}$ the local trauma that occurs while using ligature-induced periodontitis should be considered because observed modulatory effects could not be solely associated to $P$. gingivalis in this model. However, to date, no data are 
available regarding the specific effect induced by chronic mechanical trauma on programed cell death at the periodontal lesion site.

To better understand the bacterial mechanisms involved, the effects induced by $P$. gingivalis LPS were investigated. $P g$-LPS is a well-described virulence factor that activates host inflammatory response. It has already been shown that $P g$-LPS induces secretion of several proinflammatory cytokines such as TNF- $\alpha$ or IL- $1^{57}$ or extracellular matrix proteases such as cathepsins. ${ }^{58}$ In this study, $P g$-LPS exhibits cytotoxic effects in both cell types as observed in endothelial cells. ${ }^{25}$ As for the bacteria, cytotoxicity of LPS has been demonstrated to depend on the strain and structure, such as the presence of O-antigen, ${ }^{59}$ and also the cell type. ${ }^{60}$ Appealingly, LPS was found to modulate apoptosome-related pathway by increasing APAF-1 expression and caspases activity as observed in endothelial cells. ${ }^{25} \mathrm{Pg}$-LPS acts through toll-like receptors (TLRs) such as TLR- ${ }^{57}$ and TLR-4. ${ }^{59,61}$ Besides, TLRs have already been linked to apoptosis in several infectious models such as in macrophages simulated with Mycobacterium proteins. ${ }^{62,63}$ However, specific mechanisms associated with $P g$-LPS need to be elucidated.

Finally, this study demonstrated the putative role of APAF-1/XIAP in periodontal pathogenesis within soft tissues. Infection with $P$. gingivalis modulates APAF-1 apoptosome and XIAP activities in a cell type-dependent manner (Figure 8). These mechanisms may be one of those explaining the subversion of innate immune response by $P$. gingivalis that occurs during periodontitis. However, further experiments such as knock-in of Apaf-1 should be conducted to evaluate its potential impact on the prevention or management of $P$. gingivalis-associated diseases. Targeting programed cell death in a time-controlled manner may be a promising tool, as suggested for autophagy; however, specific drugs should be developed with limited risk of side effect.

\section{Acknowledgment}

We thank Dr. Thomas Décoville for his help with flow cytometric experiments.

\section{References}

1. Petersen PE, Baehni PC: Periodontal health and global public health. Periodontol 2000 2012, 60:7-14

2. Hajishengallis G: Periodontitis: from microbial immune subversion to systemic inflammation. Nat Rev Immunol 2015, 15:30-44

3. Costalonga M, Herzberg MC: The oral microbiome and the immunobiology of periodontal disease and caries. Immunol Lett 2014, 162: 22-38

4. Hajishengallis G, Lamont RJ: Breaking bad: manipulation of the host response by Porphyromonas gingivalis. Eur J Immunol 2014, 44: 328-338

5. Yilmaz O: The chronicles of Porphyromonas gingivalis: the microbium, the human oral epithelium and their interplay. Microbiology 2008, 154:2897-2903
6. Lamont RJ, Chan A, Belton CM, Izutsu KT, Vasel D, Weinberg A: Porphyromonas gingivalis invasion of gingival epithelial cells. Infect Immun 1995, 63:3878-3885

7. Pan C, Xu X, Tan L, Lin L, Pan Y: The effects of Porphyromonas gingivalis on the cell cycle progression of human gingival epithelial cells. Oral Dis 2013, 20:100-108

8. Furuta N, Takeuchi H, Amano A: Entry of Porphyromonas gingivalis outer membrane vesicles into epithelial cells causes cellular functional impairment. Infect Immun 2009, 77:4761-4770

9. Kuboniwa M, Hasegawa Y, Mao S, Shizukuishi S, Amano A, Lamont RJ, Yilmaz O: P. gingivalis accelerates gingival epithelial cell progression through the cell cycle. Microbes Infect 2008, 10:122-128

10. Mao S, Park Y, Hasegawa Y, Tribble GD, James CE, Handfield M, Stavropoulos MF, Yilmaz O, Lamont RJ: Intrinsic apoptotic pathways of gingival epithelial cells modulated by Porphyromonas gingivalis. Cell Microbiol 2007, 9:1997-2007

11. Brozovic S, Sahoo R, Barve S, Shiba H, Uriarte S, Blumberg RS, Kinane DF: Porphyromonas gingivalis enhances FasL expression via up-regulation of NFkappaB-mediated gene transcription and induces apoptotic cell death in human gingival epithelial cells. Microbiology 2006, 152:797-806

12. Stathopoulou PG, Galicia JC, Benakanakere MR, Garcia CA, Potempa J, Kinane DF: Porphyromonas gingivalis induce apoptosis in human gingival epithelial cells through a gingipain-dependent mechanism. BMC Microbiol 2009, 9:107

13. Nakhjiri SF, Park Y, Yilmaz O, Chung WO, Watanabe K, El-Sabaeny A, Park K, Lamont RJ: Inhibition of epithelial cell apoptosis by Porphyromonas gingivalis. FEMS Microbiol Lett 2001, 200:145-149

14. Lin W-C, Tsai H-F, Liao H-J, Tang C-H, Wu Y-Y, Hsu P-I, Cheng A-L, Hsu P-N: Helicobacter pylori sensitizes TNF-related apoptosis-inducing ligand (TRAIL)-mediated apoptosis in human gastric epithelial cells through regulation of FLIP. Cell Death Dis 2014, 5:e1109

15. Yamada S, Noguchi H, Tanimoto A: Critical and diverse in vivo roles of apoptosis signal-regulating kinase 1 in animal models of atherosclerosis and cholestatic liver injury. Histol Histopathol 2016, 32: 43-444

16. Song B, Zhou T, Yang WL, Liu J, Shao LQ: Programmed cell death in periodontitis: recent advances and future perspectives. Oral Dis 2016, 23:609-619

17. Zamaraev AV, Kopeina GS, Zhivotovsky B, Lavrik IN: Cell death controlling complexes and their potential therapeutic role. Cell Mol Life Sci 2015, 72:505-517

18. Ledgerwood EC, Morison IM: Targeting the apoptosome for cancer therapy. Clin Cancer Res 2009, 15:420-424

19. Riedl SJ, Salvesen GS: The apoptosome: signalling platform of cell death. Nat Rev Mol Cell Biol 2007, 8:405-413

20. Yuan S, Akey CW: Apoptosome structure, assembly, and procaspase activation. Structure 2013, 21:501-515

21. Shiozaki EN, Chai J, Rigotti DJ, Riedl SJ, Li P, Srinivasula SM, Alnemri ES, Fairman R, Shi Y: Mechanism of XIAP-mediated inhibition of caspase-9. Mol Cell 2003, 11:519-527

22. Ho AT, Li QH, Okada H, Mak TW, Zacksenhaus E: XIAP activity dictates Apaf-1 dependency for caspase 9 activation. Mol Cell Biol 2007, 27:5673-5685

23. Cain K: Chemical-induced apoptosis: formation of the Apaf-1 apoptosome. Drug Metab Rev 2003, 35:337-363

24. Greenberg DE, Sturdevant DE, Marshall-Batty KR, Chu J, Pettinato AM, Virtaneva K, Lane J, Geller BL, Porcella SF, Gallin JI, Holland SM, Zarember KA: Simultaneous host-pathogen transcriptome analysis during Granulibacter bethesdensis infection of neutrophils from healthy subjects and patients with chronic Granulomatous disease. Infect Immun 2015, 83:4277-4292

25. Bugueno IM, Khelif Y, Seelam N, Morand D-N, Tenenbaum H, Davideau J-L, Huck O: Porphyromonas gingivalis differentially modulates cell death profile in Ox-LDL and TNF-alpha pre-treated endothelial cells. PLoS One 2016, 11:e0154590 
26. Tucka J, Yu H, Gray K, Figg N, Maguire J, Lam B, Bennett M, Littlewood T: Akt1 regulates vascular smooth muscle cell apoptosis through FoxO3a and Apaf1 and protects against arterial remodeling and atherosclerosis. Arterioscler Thromb Vasc Biol 2014, 34: $2421-2428$

27. Armitage GC: Development of a classification system for periodontal diseases and conditions. Ann Periodontol 1999, 4:1-6

28. Saadi-Thiers K, Huck O, Simonis P, Tilly P, Fabre J-E, Tenenbaum H, Davideau J-L: Periodontal and systemic responses in various mice models of experimental periodontitis: respective roles of inflammation duration and Porphyromonas gingivalis infection. $\mathrm{J}$ Periodontol 2013, 84:396-406

29. Rampersad SN: Multiple applications of Alamar Blue as an indicator of metabolic function and cellular health in cell viability bioassays. Sensors (Basel) 2012, 12:12347-12360

30. Hasegawa J, Kamada S, Kamiike W, Shimizu S, Imazu T, Matsuda H, Tsujimoto Y: Involvement of CPP32/Yama(-like) proteases in Fas-mediated apoptosis. Cancer Res 1996, 56:1713-1718

31. Rosado JA, Lopez JJ, Gomez-Arteta E, Redondo PC, Salido GM, Pariente JA: Early caspase-3 activation independent of apoptosis is required for cellular function. J Cell Physiol 2006, 209:142-152

32. Ramage G, Lappin DF, Millhouse E, Malcolm J, Jose A, Yang J, Bradshaw DJ, Pratten JR, Culshaw S: The epithelial cell response to health and disease associated oral biofilm models. J Periodont Res 2016, 52:325-333

33. Liu J, Chen J, Du X, Hu L, Chen L: The expression of hBDs in the gingival tissue and keratinocytes from healthy subjects and periodontitis patients. Arch Oral Biol 2014, 59:193-198

34. Yilmaz O, Jungas T, Verbeke P, Ojcius DM: Activation of the phosphatidylinositol 3-kinase/Akt pathway contributes to survival of primary epithelial cells infected with the periodontal pathogen Porphyromonas gingivalis. Infect Immun 2004, 72:3743-3751

35. Sakanaka A, Takeuchi H, Kuboniwa M, Amano A: Dual lifestyle of Porphyromonas gingivalis in biofilm and gingival cells. Microb Pathog 2016, 94:42-47

36. Takeuchi H, Furuta N, Morisaki I, Amano A: Exit of intracellular Porphyromonas gingivalis from gingival epithelial cells is mediated by endocytic recycling pathway. Cell Microbiol 2011, 13:677-691

37. Al-Taweel FB, Douglas CW, Whawell SA: The periodontal pathogen Porphyromonas gingivalis preferentially interacts with oral epithelial cells in S phase of the cell cycle. Infect Immun 2016, 84:1966-1974

38. Shaik-Dasthagirisaheb YB, Huang N, Weinberg EO, Shen SS, Genco CA, Gibson FC III: Aging and contribution of MyD88 and TRIF to expression of TLR pathway-associated genes following stimulation with Porphyromonas gingivalis. J Periodont Res 2015, 50:89-102

39. Wu Y, Dong G, Xiao W, Xiao E, Miao F, Syverson A, Missaghian N, Vafa R, Cabrera-Ortega AA, Rossa C Jr, Graves DT: Effect of aging on periodontal inflammation, microbial colonization, and disease susceptibility. J Dent Res 2016, 95:460-466

40. Ebersole JL, Kirakodu S, Novak MJ, Exposto CR, Stromberg AJ, Shen S, Orraca L, Gonzalez-Martinez J, Gonzalez OA: Effects of aging in the expression of NOD-like receptors and inflammasomerelated genes in oral mucosa. Mol Oral Microbiol 2016, 31:18-32

41. Desta T, Graves DT: Fibroblast apoptosis induced by Porphyromonas gingivalis is stimulated by a gingipain and caspase-independent pathway that involves apoptosis-inducing factor. Cell Microbiol 2007, 9:2667-2675

42. Liu J, Tang X, Li C, Pan C, Li Q, Geng F, Pan Y: Porphyromonas gingivalis promotes the cell cycle and inflammatory cytokine production in periodontal ligament fibroblasts. Arch Oral Biol 2015, 60: $1153-1161$

43. Chang M-C, Tsai Y-L, Chen Y-W, Chan C-P, Huang C-F, Lan W-C, Lin CC, Lan W-H, Jeng J-H: Butyrate induces reactive oxygen species production and affects cell cycle progression in human gingival fibroblasts. J Periodont Res 2013, 48:66-73
44. Sawa T, Nishimura F, Ohyama H, Takahashi K, Takashiba S, Murayama Y: In vitro induction of activation-induced cell death in lymphocytes from chronic periodontal lesions by exogenous Fas ligand. Infect Immun 1999, 67:1450-1454

45. Chowdhury I, Tharakan B, Bhat GK: Current concepts in apoptosis: the physiological suicide program revisited. Cell Mol Biol Lett 2006, 11:506-525

46. Rahman MA, Shirai M, Aziz MA, Ushirokita R, Kubota S, Suzuki H, Azuma Y: An epistatic effect of apaf-1 and caspase-9 on chlamydial infection. Apoptosis 2015, 20:1271-1280

47. Halder UC, Bagchi P, Chattopadhyay S, Dutta D, Chawla-Sarkar M: Cell death regulation during influenza A virus infection by matrix (M1) protein: a model of viral control over the cellular survival pathway. Cell Death Dis 2011, 2:e197

48. Ke X, Lei L, Li H, Li H, Yan F: Manipulation of necroptosis by Porphyromonas gingivalis in periodontitis development. Mol Immunol 2016, 77:8-13

49. Riedl SJ, Renatus M, Schwarzenbacher R, Zhou Q, Sun C, Fesik SW Liddington RC, Salvesen GS: Structural basis for the inhibition of caspase-3 by XIAP. Cell 2001, 104:791-800

50. Vasilikos L, Spilgies LM, Knop J, Wong WW: Regulating the balance between necroptosis, apoptosis and inflammation by inhibitors of apoptosis proteins. Immunol Cell Biol 2017, 95:160-165

51. Olsen I, Yilmaz O: Modulation of inflammasome activity by Porphyromonas gingivalis in periodontitis and associated systemic diseases. J Oral Microbiol 2016, 8:30385

52. Huck O, Elkaim R, Davideau J-L, Tenenbaum H: Porphyromonas gingivalis-impaired innate immune response via NLRP3 proteolysis in endothelial cells. Innate Immun 2015, 21:65-72

53. Zhao P, Liu J, Pan C, Pan Y: NLRP3 inflammasome is required for apoptosis of Aggregatibacter actinomycetemcomitans-infected human osteoblastic MG63 cells. Acta Histochem 2014, 116:1119-1124

54. Shi C-S, Kehrl JH: Cytochrome c negatively regulates NLRP3 inflammasomes. PLoS One 2016, 11:e0167636

55. Ong JD, Mansell A, Tate MD: Hero turned villain: NLRP3 inflammasome-induced inflammation during influenza A virus infection. J Leukoc Biol 2017, 101:863-874

56. Graves DT, Kang J, Andriankaja O, Wada K, Rossa C Jr: Animal models to study host-bacteria interactions involved in periodontitis. Front Oral Biol 2012, 15:117-132

57. Kocgozlu L, Elkaim R, Tenenbaum H, Werner S: Variable cell responses to P. gingivalis lipopolysaccharide. J Dent Res 2009, 88: $741-745$

58. Elkaim R, Werner S, Kocgozlu L, Tenenbaum H: P. gingivalis regulates the expression of Cathepsin B and Cystatin C. J Dent Res 2008 , 87:932-936

59. Soto C, Bugueño I, Hoare A, Gonzalez S, Venegas D, Salinas D, Melgar-Rodríguez S, Vernal R, Gamonal J, Quest AF, PérezDonoso JM, Bravo D: The Porphyromonas gingivalis $\mathrm{O}$ antigen is required for inhibition of apoptosis in gingival epithelial cells following bacterial infection. J Periodont Res 2015, 51:518-528

60. Murray DA, Wilton JM: Lipopolysaccharide from the periodontal pathogen Porphyromonas gingivalis prevents apoptosis of HL60derived neutrophils in vitro. Infect Immun 2003, 71:7232-7235

61. Yang X, Zhang J, Ni J, Ouyang B, Wang D, Luo S, Xie B, Xuan D: Toll-like receptor 4-mediated hyper-responsiveness of gingival epithelial cells to lipopolysaccharide in high-glucose environments. J Periodontol 2014, 85:1620-1628

62. Lee K-I, Choi H-G, Son Y-J, Whang J, Kim K, Jeon HS, Park H-S, Back YW, Choi S, Kim S-W, Choi CH, Kim H-J: Mycobacterium avium MAV2052 protein induces apoptosis in murine macrophage cells through Toll-like receptor 4. Apoptosis 2016, 21:459-472

63. Tiwari B, Ramakrishnan UM, Raghunand TR: The Mycobacterium tuberculosis protein pair PE9 (Rv1088)-PE10 (Rv1089) forms heterodimers and induces macrophage apoptosis through Toll-like receptor 4. Cell Microbiol 2015, 17:1653-1669 